\title{
Naloxone as a technology of solidarity: history of opioid overdose prevention
}

\author{
n Cite as: CMAJ 2019 August 26;191:E945-6. doi: 10.1503/cmaj.190257
}

CMAJ Podcasts: author interview at https://soundcloud.com/cmajpodcasts/190257-medsoc

$\mathrm{T}$ -shirts sport the slogan "Keep Calm and Carry Naloxone." "HERO" bracelets signal someone carries take-home naloxone. Naloxone Ninjas tweet, tally lives saved and distribute naloxone kits. Silver ribbons mark International Overdose Awareness Day, modelled on the red ribbons worn in solidarity with patients living with HIV/AIDS. Promotional campaigns throughout the world uphold naloxone as a miraculous life-saver. A dedicated contingent of harm-reduction activists, advocates, clinicians and scientists have enrolled institutions, organizations and governments in support of harm reduction and prevention of overdose deaths (Appendix 1 , available at www.cmaj.ca/lookup/ suppl/doi:10.1503/cmaj.190257/-/DC1). Naloxone has come to matter as the places and people affected by deaths from opioid overdose have prompted "rescues" or "reversals" from Australia, Britain, Canada and the United States to Estonia, Vietnam and Iran. Canada made naloxone available without prescription in March 2016 - a status still unrealized in the US, where each day nearly 150 preventable deaths occur and close to 1000 people are treated for opioidrelated injuries. ${ }^{1,2}$

Like any technology, naloxone has passed through social cycles of innovation, adoption and backlash - social processes that have brought activists and public health officials, law enforcement, and private medicine into conflict over the terms on which opioids would be used in societies that are both deeply dependent and deeply ambivalent about them. For its protagonists, naloxone's story is one of a "technology of solidarity," but naloxone's predecessor was initially used as a "technology of suspicion." ${ }^{3}$

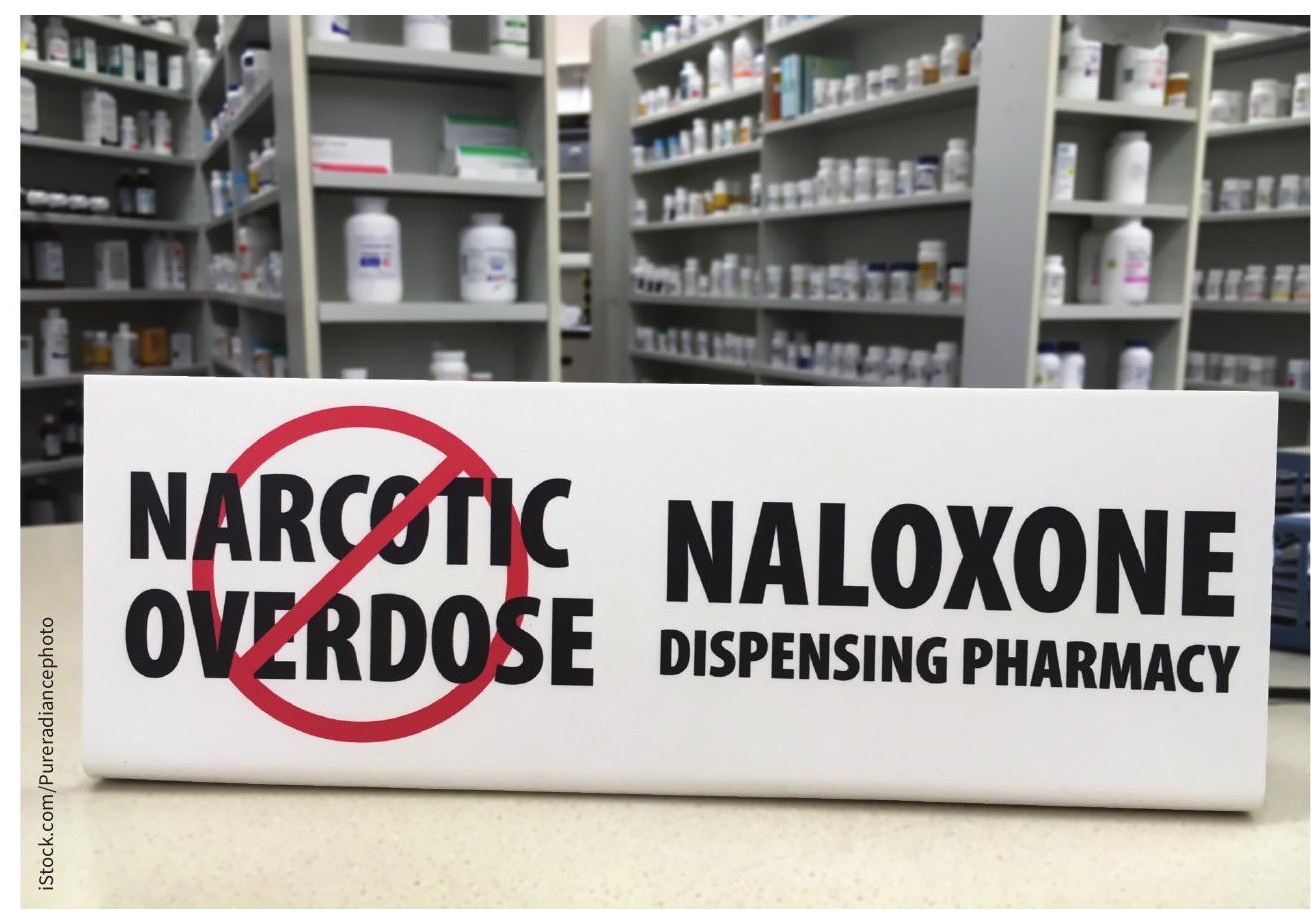

Naloxone's predecessor nalorphine ( $\mathrm{N}$-allyl-normorphine), the first narcotic antagonist to be used clinically, was known by its Merck tradename, Nalline. In Alameda County, where Oakland, California, is located, police used it as a tool of surveillance and social control, a pharmacological "tell" to detect who was dependent on narcotics. ${ }^{4}$ Touted as a boon to "police science," Nalline was used in California cities such as Oakland, Los Angeles and Eureka from the 1950s and well into the 1970s, long after its successor, naloxone, had appeared.

Nalorphine's legal path stretched all the way up to the US Supreme Court. A landmark decision in Robinson v. California (1962) on the Eighth Amendment right to be free of cruel and unusual punishment read in part, "It is unlikely that any state at this moment in history would attempt to make it a criminal offense for a person to be mentally ill, or a leper, or to be afflicted with a venereal disease .... Even one day in prison would be a cruel and unusual punishment for the 'crime' of having a common cold." ${ }^{5}$ As "cruel and unusual punishment," nalorphine precipitated dysphoric withdrawal when administered to individuals dependent on opioids, but the Nalline test provided seemingly incontrovertible scientific evidence of narcotics use. Individuals suspected of using narcotics were continuously surveilled, and many of them were put on periodic administration of nalorphine because it was considered to deter heroin use. 
The testing program was integral to the State of California's civil commitment program. Under the guise of a therapeutic regime, the California program restricted the very movements of those dependent on narcotics. Adopting Nalline as their "weapon of choice in the narcotic war," Humboldt County sought to prevent "addicts" (and ex-cons) from being employed in lumber mills. Although regularly used to reverse anesthesia-induced overdose in hospital operating rooms, Nalline never appeared outside hospital settings. One of the chief architects of Oakland's program, Thorvald Brown, told the story of 20-year-old Toby, whose friends dumped him at a hospital emergency entrance in a deep coma after trying to revive him in a cold bath. ${ }^{4}$ Revived briefly after administration of nalorphine and oxygen, Toby "sat up and tried to speak but fell back dead" - a death Brown considered "typical of the ignorant manner in which addicts indifferently dabble with drugs and ignore the deathdealing power of the unknown quantity and quality of the junk they shoot into their veins." 4 So potent did Brown find this dealing in death that he felt that the life of an addict "must be truly charmed, for the mystery is how do they survive."4

Parties of police toured Oakland's model Nalline program, starting up programs of their own in St. Louis, Missouri; Hong Kong; Singapore; and Texas. Despite little or no evidence that it accomplished what its proponents claimed it did, the Nalline test may have had the unintended consequence of encouraging amphetamine consumption because it did not detect "speed." ${ }^{\text {As }}$ drug users became familiar with the surveillant, dysphoric and punitive aspects of the narcotic antagonist, they took measures to evade it.

While Nalline clinics phased out in the 1970s, the test remains admissible in the most recent Jefferson's California Evidence Benchbook. Despite US Food and
Drug Administration (FDA) approval of naloxone for the purpose of reversing overdose in 1971, naloxone did not abruptly displace nalorphine, despite its relative effectiveness. Developed in the early 1960 s by Jack Fishman, whose scientific career was spent studying steroids and hormones at the Sloan-Kettering Institute for Cancer Research, naloxone was the outcome of the quest to reduce one of the less savory aspects of chronic opiate use: constipation. Fishman was moonlighting for Mozes J. Lewenstein, head of the Endo Laboratories Narcotics Division in Richmond Hills, New York, when he synthesized naloxone. Founded in 1920 as a family-run business, Endo enjoyed its first pharmaceutical success in 1948 with Coumadin (warfarin), the anticoagulant still used today. Naloxone's developers saw little market for it. Not until 1971 did they seek FDA approval, which was obtained with little fanfare. Use was largely confined to hospital settings and emergency medical response.

Popular access to naloxone was first facilitated in Italy in 1991 in response to a heroin epidemic that occurred in northern Italian cities in the late 1980s. ${ }^{7}$ In Australia and the United Kingdom, opinion leaders broached possible "take-home" naloxone in the early 1990s, but did not implement programs until the early 2000s (although these countries integrated other forms of harm reduction into their national health care systems). Expert advocacy in the UK and European Union was closely tied to the making of evidence-based policy. Those devoted to reducing preventable deaths through naloxone access worked hand-inhand with pharmaceutical manufacturers to develop new formulations and delivery systems; others worked with regional and local governments, public health departments and institutions to respond to public health needs. Needle exchange was illegal in the US, which lacks national health care; underground exchanges were organized in response to HIV/AIDS in San Francisco,
New York, Chicago, Seattle and Tacoma. Direct provision of naloxone was slow because activists worked within different political cultures and legal frameworks in each state. The Chicago Recovery Alliance redefined recovery as "any positive change," and began direct naloxone provision in the late 1990 s, serving as a national distribution hub.

In "liberating" naloxone from the medical and scientific enclaves to which it was confined in its first four decades, partisans became enrolled in the harm-reduction movement. For many, naloxone is an antidote to malaise and a symbol of collective action for social change - a technology of solidarity. The story of naloxone is really a story about the people of naloxone - protagonists who generate, unsettle and embody knowledge. To them, it matters that we live in societies where such efforts are encouraged by those who govern us.

\section{Nancy D. Campbell PhD}

Department of Science and Technology

Studies, Sage Labs 5202, Rensselaer

Polytechnic Institute, Troy, NY

\section{References}

1. Emergency medical services data on suspected opioid-related overdoses in Canada. Ottawa: Public Health Agency of Canada; modified 2019 Apr. 10. Available: https://infobase.phac-aspc. gc.ca/datalab/national-surveillance-opioid-harms .html (accessed 2019 Apr. 29).

2. Opioid overdose. Atlanta: Centers for Disease Control and Prevention; updated 2018 Oct. 19. Available: www.cdc.gov/drugoverdose/?s_cid =ostltsdyk_cs_636 (accessed 2019 Apr. 29)

3. Campbell ND. Technologies of suspicion: coercion and compassion in post-disciplinary surveillance regimes. Surv Soc 2004;2:78-92.

4. Brown T. The enigma of drug addiction. Springfield (IL): Charles C. Thomas; 1961.

5. Robinson v. California, 370 U.S. 660 (1962).

6. Grupp SE. Addict mobility and the Nalline test. Br J Addict Alcohol Other Drugs 1968;63:227-36.

7. Preventing opioid overdose deaths: a research on the Italian naxolone distribution model [report]. Forum Droghe; 2016.

This article has been peer reviewed.

Competing interests: None declared. 